\title{
Evolutionary impact assessment of the North Sea plaice fishery
}

\author{
Fabian M. Mollet, Jan Jaap Poos, Ulf Dieckmann, and Adriaan D. Rijnsdorp
}

\begin{abstract}
There is growing evidence that fishing causes evolution in life-history traits that affect the productivity of fish stocks. Here we explore the impact of fisheries-induced evolution (FIE) on the productivity of North Sea plaice (Pleuronectes platessa) using an ecogenetic, individual-based model by comparing management scenarios with and without an evolutionary response. Under status-quo management, plaice evolve towards smaller size at age, earlier maturation, and higher reproductive investment. Current reference points of maximum sustainable yield (MSY) and corresponding fishing-mortality rate $\left(F_{\text {MSY }}\right)$ that ignore FIE will decrease and cannot be considered sustainable. The nature and extent of the change through FIE depend on fishing effort and selectivity. The adverse evolutionary effects can be reduced - and even reversed - by implementing a dome-shaped exploitation pattern protecting the large fish. The evolutionarily sustainable maximum yield can be obtained by combining such a dome-shaped exploitation pattern with a reduction in fishing mortality and an increase in mesh size; it is similar to the MSY that would apply if life-history traits were static. Fisheries managers will need to trade off the short-term loss in yield associated with evolutionarily informed management with the long-term loss in yield FIE causes under evolutionarily uninformed management.
\end{abstract}

Résumé : Il apparaît de plus en plus clair que la pêche causerait l'évolution de caractères du cycle biologique qui ont une incidence sur la productivité des stocks de poi ssons. Nous examinons l'incidence de l'évolution induite par la pêche (EIP) sur la pr oductivité des plies (Pleuronectes platessa) de la mer du Nord à l'aide d'un modèle écogénétique basé sur l'individu, en comparant des scénarios de gestion avec et sans réaction évol utive. Dans une gestion en mode statu quo, les plies évoluent vers de plus faibles tailles selon l'âge, une maturation plus pr écoce et un investissement accru dans la reproduction. Les points de référence actuels du rendement équilibré maximal $(\mathrm{REM})$ et du taux de mortalité par pêche correspondant $\left(F_{\mathrm{REM}}\right)$ qui ne tiennent pas compte de l'EIP sont appelés à diminuer et ne peuvent être considérés comme durables. La nature et l'ampleur des changements découlant de l'EIP dépendent de l'effort de pêche et de sa sélectivité. Les effets a dverses sur l'évolution peuvent être réduits, voire inversés, en appliquant une courbe d'exploitation en forme de dôme, qui protège les poissons de grande taille. Le REM durable au vu de l'évolution peut être obtenu en combinant une telle courbe d'exploitation à une réduction de la mortalité par pêche et une augmentation de la taille des mailles des filets; ce rendement est semblable au rendement équil ibré maximal qui s'appliquerait si les caractères du cycle biologique étaient statiques. Les gestionnaires des pêches devront soupeser les conséquences relatives de la réduction du rendement à court terme associée à une ge stion tenant compte de l'évolution et de la réduction du rendement à long terme causée par l'EIP si la gestion ne tient pas compte de l'évolution. [Traduit par la Rédaction]

\section{Introduction}

Fishing-mortality rates have increased substantially with industrialization, and concerns have been raised that this may cause fisheries-induced evolution (FIE) on decadal time scales (Law and Grey 1989; Rijnsdorp 1993a; Stokes et al. 1993; Heino 1998). Controlled experiments on different fish species have confirmed that strong selection may result in substantial life-history evolution within a few generations (Reznick et al. 1990; Conover and Munch 2002; van Wijk et al. 2013). Analyses of long-term datasets have supported the understanding that FIE in maturation schedules, reproductive investments, and growth rates can occur in exploited populations within a few decades (Olsen et al. 2004; Jørgensen et al. 2007; Kuparinen and Merilä 2007). Models of evolutionary dynamics under different fishing regimes have corroborated this finding (Thériault et al. 2008; Dunlop et al. 2009; Enberg et al. 2009; Okamoto et al. 2009; Eikeset et al. 2013).
Evolutionary changes are directional towards the evolutionary equilibrium engendered by a higher fishing mortality and are expected to reverse only slowly once fishing mortality is reduced (Law 2000; Dunlop et al. 2009; Enberg et al. 2009). Moreover, FIE may erode the productivity of a stock, as the commonly observed shift towards earlier maturation and increased reproductive investment reduce somatic growth (Law and Grey 1989) and may affect density-dependent feedbacks determining recruitment (Heino et al. 2013; Kuparinen et al. 2014), calling for a Darwinian view on fisheries management (Conover 2000; Jørgensen et al. 2007; Dieckmann et al. 2009).

The maximum sustainable yield (MSY) and corresponding fishing-mortality rate ( $\left.F_{\mathrm{MSY}}\right)$ have traditionally been used as reference points in fisheries management (Beverton and Holt 1957). Despite being criticized (Larkin 1977; Hilborn and Walters 1992; Caddy and Mahon 1995), they have regained a central place in

Received 22 December 2014. Accepted 1 November 2015.

F.M. Mollet.* Wageningen IMARES - Institute for Marine Resources and Ecosystem Studies, P.O. Box 68, 1970 AB, IJmuiden, the Netherlands; Evolution and Ecology Program, International Institute for Applied Systems Analysis, Schlossplatz 1, A-2361 Laxenburg, Austria.

J.J. Poos. Wageningen IMARES - Institute for Marine Resources and Ecosystem Studies, P.O. Box 68, 1970 AB, IJmuiden, the Netherlands.

U. Dieckmann. Evolution and Ecology Program, International Institute for Applied Systems Analysis, Schlossplatz 1, A-2361 Laxenburg, Austria.

A.D. Rijnsdorp. Wageningen IMARES - Institute for Marine Resources and Ecosystem Studies, P.O. Box 68, 1970 AB, IJmuiden, the Netherlands;

Aquaculture and Fisheries group, Wageningen University, P.O. Box 338, 6700 AH, Wageningen, the Netherlands.

Corresponding author: Fabian Mollet (email: fabian.mollet@blueyou.com).

*Present address: Blueyou Consulting Ltd., Zentralstr. 56, 8003 Zürich, Switzerland.

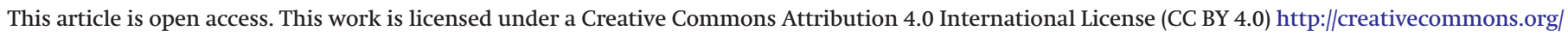
licenses/by/4.0/deed.en_GB. 


\section{Pagination not final (cite DOI) / Pagination provisoire (citer le DOI)}

fisheries management since the Johannesburg Declaration agreed to maintain or restore fish stocks to levels that can produce the MSY (United Nations 2002; Heino et al. 2013). MSY is normally estimated under the assumption of time-invariant parameters for growth, maturation, fecundity, stock-recruitment relationship, natural mortality, and exploitation pattern, even though, when these parameters change in response to fishing, the reference points will change accordingly (Heino et al. 2013).

Here we analyse the evolutionary consequences of fishing for North Sea plaice (Pleuronectes platessa) and explore which management measures may reduce fishing's evolutionary impact on traits and yield. In North Sea plaice, FIE has been reported in the onset of maturation, reproductive investment, and growth rate (Rijnsdorp 1993a; Grift et al. 2003; Rijnsdorp et al. 2005; van Walraven et al. 2010). We use an ecogenetic model according to Dunlop et al. (2009), calibrated for North Sea plaice (Mollet 2010), to estimate the evolutionary effects of current management and to explore management scenarios aimed at mitigating these evolutionary effects. We examine how changes in fishing selectivity, in particular a dome-shaped exploitation pattern (Law 2007; Hutchings 2009; Jørgensen et al. 2009), can reduce, for a range of fishing mortalities and mesh sizes, the evolution of life-history traits and influence the fishery's yield. To estimate the consequences of ignoring FIE in fisheries management, the results are compared with those of a model with static life-history traits. As such, our study is an example of an evolutionary impact assessment (EvoIA) as first suggested by Jørgensen et al. (2007) and elaborated upon by Laugen et al. (2014).

\section{Materials and methods}

\section{Ecogenetic model}

Our results are derived from an individual-based ecogenetic model (Dunlop et al. 2009). Each year, a cohort of individuals is born. Individuals are characterized by three genetic traits that directly and indirectly govern growth by affecting energy acquisition $(a)$, reproduction $(c)$, and maturation $(u)$. Individuals inherit the mean genetic trait values of their parents with variation. Selection occurs because individuals differ in their survival probability and reproductive success in dependence on these genetic traits. The model includes life-history trade-offs between growth and survival and between reproduction and survival and quantifies both the phenotypically plastic response and the genetic response to fishing. Modelled population numbers are set at $\sim 50000$ individuals in the unexploited population and drop to $\sim 25000$ individuals when the population is exploited at an instantaneous fishing-mortality rate of $F=0.5$ year $^{-1}$.

The model is calibrated for female North Sea plaice and reproduces the observed changes in life-history parameters in the 20th century (Mollet 2010; Mollet et al. 2015). In accordance with the historical course of exploitation in North Sea plaice (Rijnsdorp and Millner 1996), the current population is modelled after a period of 100 years of intensive fishing. Starting from this reference model, management scenarios are evaluated over time periods of $10,50,100$, and 1000 years. The rationale for including the long time horizon of 1000 years in our analyses is that we want to know the evolutionary equilibrium the population is eventually expected to approach. Naturally, the shorter time horizons of 10, 50, and 100 years are much more relevant from a management perspective. The evolutionary effects are assessed in terms of yield, maximum yield, and corresponding fishing mortality. We examine management scenarios covering various levels of fishing mortality, a range of mesh sizes, and different shapes of exploitation patterns, varying from flat-topped to fully dome-shaped.

Details on the model equations, parameterization, and calibration for North Sea plaice are given by Mollet (2010) and in Appendix A. Here we present a summary of the model's salient aspects.
Somatic growth and reproductive investment follow the energy-allocation model by West et al. (2001):

$$
\frac{\mathrm{d} w}{\mathrm{~d} t}=a w^{3 / 4}-b w-\left\{\begin{array}{cl}
0 & \text { if } t<t_{\mathrm{mat}} \\
c w & \text { if } t \geq t_{\mathrm{mat}}
\end{array}\right.
$$

where $w$ is an individual's somatic mass, $t$ is its age, and $t_{\text {mat }}$ is its age at maturation. The mass-specific energy-acquisition rate $a$ and the mass-specific reproductive-investment rate $c$ are allowed to evolve, while the mass-specific maintenance rate $b$ is assumed to be constant. For smaller fish $(<25 \mathrm{~cm})$, the mass-specific energyacquisition rate $a$ is reduced by crowding as a function of the biomass of the smaller fish (Rijnsdorp and van Leeuwen 1996; Teal et al. 2008). Since the model is run in yearly time steps, we assume a constant relationship between body mass and body length. Maturation is defined by a maturation reaction norm (Stearns and Koella 1986), which is assumed to be linear with intercept $u$ and slope $s$ :

$$
l_{\mathrm{p} 50}(t)=u+s t
$$

Maturation is a probabilistic process, and $l_{\mathrm{p} 50}$ defines the reactionnorm midpoints (i.e., the body lengths at which the probability of maturing reaches $50 \%$ ). Using a probabilistic maturation reaction norm (PMRN; Heino et al. 2002), we assume that for any given combination of age and size, the probability of maturing is given by

$$
p_{\text {mat }}(l, t)=1 /\left\{1+\exp \left(-\left[l(t)-l_{\mathrm{p} 50}(t)\right] / \phi\right)\right\}
$$

where $l$ is body length, and $\phi$ is a scaling parameter determining the width $d$ of the PMRN (i.e., the difference in body length over which maturation probability rises from $25 \%$ to $75 \%$ ) according to $d=2 \phi \operatorname{logit}(0.75)$.

Natural mortality is size-dependent and consists of three components: a size-dependent predation mortality rate $m_{\mathrm{p}}$, an acquisition-dependent foraging mortality rate $m_{\mathrm{f}}$, and an investment-dependent reproduction mortality rate $m_{\mathrm{r}}$. Here, $m_{\mathrm{f}}$ accounts for the growth-survival trade-off and depends on the mass-specific energy-acquisition rate $a$. Likewise, $m_{\mathrm{r}}$ accounts for the reproduction-survival trade-off and depends on the reproductive investment relative to body mass (expressed in terms of the gonadosomatic index, GSI; i.e., as the ratio of gonadic mass and somatic mass). Through these components, natural mortality decreases from $M=0.23$ year $^{-1}$ at age 0 to $M=0.1$ year $^{-1}$ at ages 3 years and older, mainly due to a decrease in predation mortality.

Recruitment is modelled according to the Beverton-Holt stockrecruitment relationship. The parameters of this relationship are set to keep recruitment nearly constant over the range of spawning biomasses typically observed in our model. The rationale for this choice is twofold. First, the empirical data do not suggest that recruitment decreases at low levels of spawning stock biomass (ICES 2011). Second, this allowed us to evaluate the consequences of evolutionary changes in growth and reproduction without these being confounded by possible changes in recruitment. As we did not attempt to calibrate our model to match the population biomass of North Sea plaice estimated by the stock assessment, the yield reported in this study is expressed in relative terms when illustrating changes over time and differences between scenarios.

\section{Exploitation patterns}

An exploitation pattern defines how the instantaneous fishingmortality rate experienced by an individual fish (Sampson and Scott 2012) depends on its size, age, or stage. Two key factors shaping an exploitation pattern are mesh selection and the 
Fig. 1. Considered modifications of the status-quo exploitation pattern (left panel). An increase in mesh size $\psi$ results in a horizontal shift of the exploitation pattern to the right (upper middle panel), while a decrease in relative availability $\delta$ results in a reduction of the fishing mortality of larger fish (lower middle panel). To keep the population's target fishing-mortality rate $F$ fixed under these modifications, the maximum exploitation rate $F_{\max }$ is adjusted so as to compensate for the resultant changes in the size distribution of the exploitable population (right panels).

Status quo

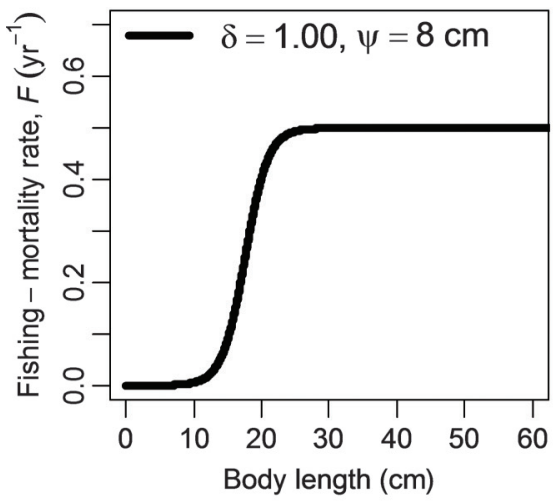

Availability
$F_{\max }$ fixed
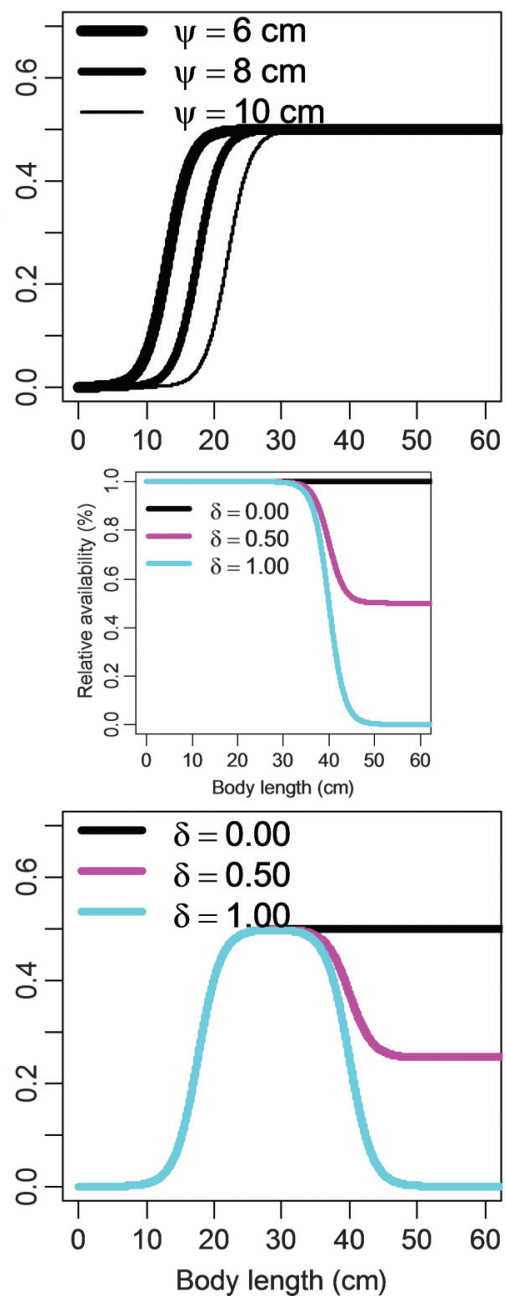

$F$ fixed

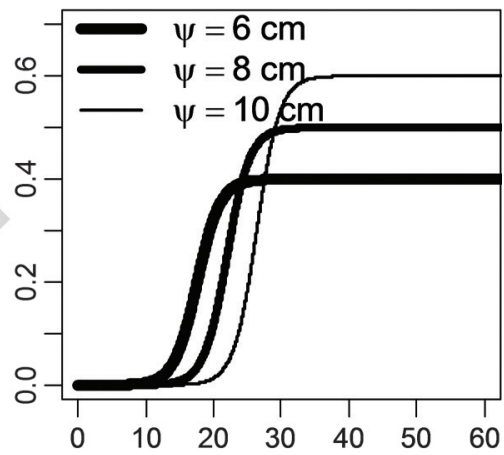

relative availability of different fish on the fishing grounds. The fishing mortality resulting from an exploitation pattern is scaled by its maximum exploitation level ( $F_{\text {max }}$; Fig. 1$)$.

For bottom trawls such as those used in the flatfish fisheries, the mesh selection can be described by a logistic curve, defined by the mesh size $\psi$ and a species-specific mesh-selection factor $\lambda$; at body length $l=\lambda \psi$, half of the fish are retained by the trawl, with fewer below and more above that length. In North Sea plaice, the exploitation pattern can be dome-shaped owing to differences in the geographic distribution of size classes and age groups; larger plaice occur in deeper water and disperse over a wider area during the feeding period than smaller plaice (Rijnsdorp and Millner 1996; van Overzee and Rijnsdorp 2015). The dome-shaped exploitation pattern is modelled by including an availability function that drops from nearly $100 \%$ for very small fish to a minimal value of $1-\delta$ for very large fish. At body length $l=l_{\mathrm{a}}\left(\right.$ with $\left.l_{\mathrm{a}}>\lambda \psi\right)$, relative availability equals $1-\delta / 2$. The parameter $\delta$ thus determines the shape of the exploitation pattern; while the exploitation pattern is flat-topped for $\delta=0$, it becomes more and more dome-shaped as $\delta$ is increased towards 1 (Fig. 1). Combining the effects of mesh selection (first factor) and relative availability (second factor), the exploitation pattern of plaice can thus be described by

$$
F_{l}=\frac{F_{\max }}{1+\exp (-\varphi[l-\lambda \psi])}\left\{1-\delta+\frac{\delta}{1+\exp \left(-\varepsilon\left[l_{\mathrm{a}}-l\right]\right)}\right\}
$$

where $F_{\max }$ is the fishing-mortality rate of the size classes that are maximally exploited. Thus, $F_{\max }$ can be considered to be proportional to fishing effort. The parameters $\varphi$ and $\varepsilon$ respectively determine how steeply fishing mortality increases around $l=\lambda \psi$ because of mesh selection and decreases around $l=l_{\mathrm{a}}$ because of relative availability.

The mortality rate $F_{\text {pop }}$ experienced by the population as a whole is given by the mean of the size-specific fishing-mortality rate $F_{l}$ weighted by the size distribution of the population. To realize a target fishing-mortality rate $F, F_{\max }$ thus needs to be adjusted when the size distribution of the exploited population changes. Figure 1 illustrates the changes in $F_{\max }$ required to compensate for a change in mesh size (upper right panel) or relative 


\section{Pagination not final (cite DOI) / Pagination provisoire (citer le DOI)}

availability (lower right panel). In our model, $F_{\text {pop }}$ is estimated from the annual decline in the number of fish of ages 2 and older, correcting for the number of fish that died from natural causes. On this basis, $F_{\max }$ is adjusted each year according to the ratio of $F$ and $F_{\text {pop }}$ in the previous year:

$$
\mathrm{F}_{\max , y}=\mathrm{F}_{\max , y-1} \mathrm{~F} / \mathrm{F}_{\mathrm{pop}, y-1}
$$

\section{Management scenarios}

Previous studies have shown that the level of fishing mortality, as well as the shape of the exploitation pattern, influence the evolutionary response to fishing (Hutchings 2009; Jørgensen et al. 2009). Managers can change the exploitation pattern by setting minimum mesh sizes, establishing size slots (defined by minimum and (or) maximum harvestable sizes), implementing seasonal or area closures, and imposing gear restrictions.

We explore the combined effects of changing a mesh-size regulation $(\psi=4,6,8,10,12 \mathrm{~cm})$ and the shape of the exploitation pattern (flat-topped to fully dome-shaped: $\delta=0,0.25,0.5,0.75,1$ ). Since the definition of MSY is problematic when accounting for evolutionary changes in life-history traits, we refer to maximum yield (MY) and denote the corresponding mortality by $F_{M Y}$ throughout this paper. These quantities are estimated by running our model for different levels of fishing mortality $(F=0,0.01$, $0.02, \ldots, 1$ year $\left.^{-1}\right)$. The MY and corresponding $F_{M Y}$ thus represent the evolutionarily stable MSY and $F_{M S Y}$ after the population has reached its evolutionary equilibrium.

As a baseline, we consider 100 years of exploitation before present at $F=0.5$ year $^{-1}, \delta=0$, and $\psi=8 \mathrm{~cm}$, reflecting the average fishing mortality and exploitation pattern observed during the 20th century (Rijnsdorp and Millner 1996). For reference, this status-quo scenario is run for another 1000 years. Results are compared, inter alia, with those for $F=0.3$ year $^{-1}$, consistent with the current management objective for North Sea plaice (ICES 2014).

\section{Evolutionary impact assessment}

To assess management scenarios that help mitigate FIE, the incurred short-term losses in yield need to be weighed against the accrued long-term gains (Laugen et al. 2014). For each year $y$ a management scenario is evaluated, we therefore compare the yield $Y_{\text {evol, } y}$ resulting in the evolutionary model with the yield $Y_{\text {static } y}$ resulting in a corresponding nonevolutionary model, in which genetic trait values are kept static at present values and population changes occur only because of demographic processes. The evolutionary impact $I_{y}$ in year $y$ is then estimated as the yield change $Y_{\mathrm{evol}, y}-Y_{\text {static } y}$ relative to the yield $Y_{\mathrm{evol}, 0}$ at the start of the management evaluation:

$$
I_{y}=\left(Y_{\text {evol }, y}-Y_{\text {static }, y}\right) / Y_{\text {evol, } 0}
$$

\section{Results}

\section{Trait evolution}

Under status-quo management $\left(F=0.5\right.$ year $^{-1}, \delta=0$, and $\psi=$ $8 \mathrm{~cm}$ ), the population's life history evolves towards a reduced mass-specific energy-acquisition rate, a lower PMRN, and a higher mass-specific reproductive-investment rate (Fig. 2). After 100 years, the population continues to evolve and approaches an evolutionary equilibrium after about 1000 years when the massspecific energy-acquisition rate and the PMRN stabilize, while the mass-specific reproductive-investment rate is still increasing. In this way, the population evolves to a state of dwarfism, with a mass-specific energy-acquisition rate a about three times lower, a mass-specific reproductive-investment rate $c$ about twice as high, and a PMRN intercept $u$ about five times lower than at the model run's beginning (Fig. 2). This means that fish mature shortly after birth and invest almost all their acquired energy into reproduction; with little investment into somatic growth, they thus reach only a small maximum body size of less than $10 \mathrm{~cm}$ (not shown).

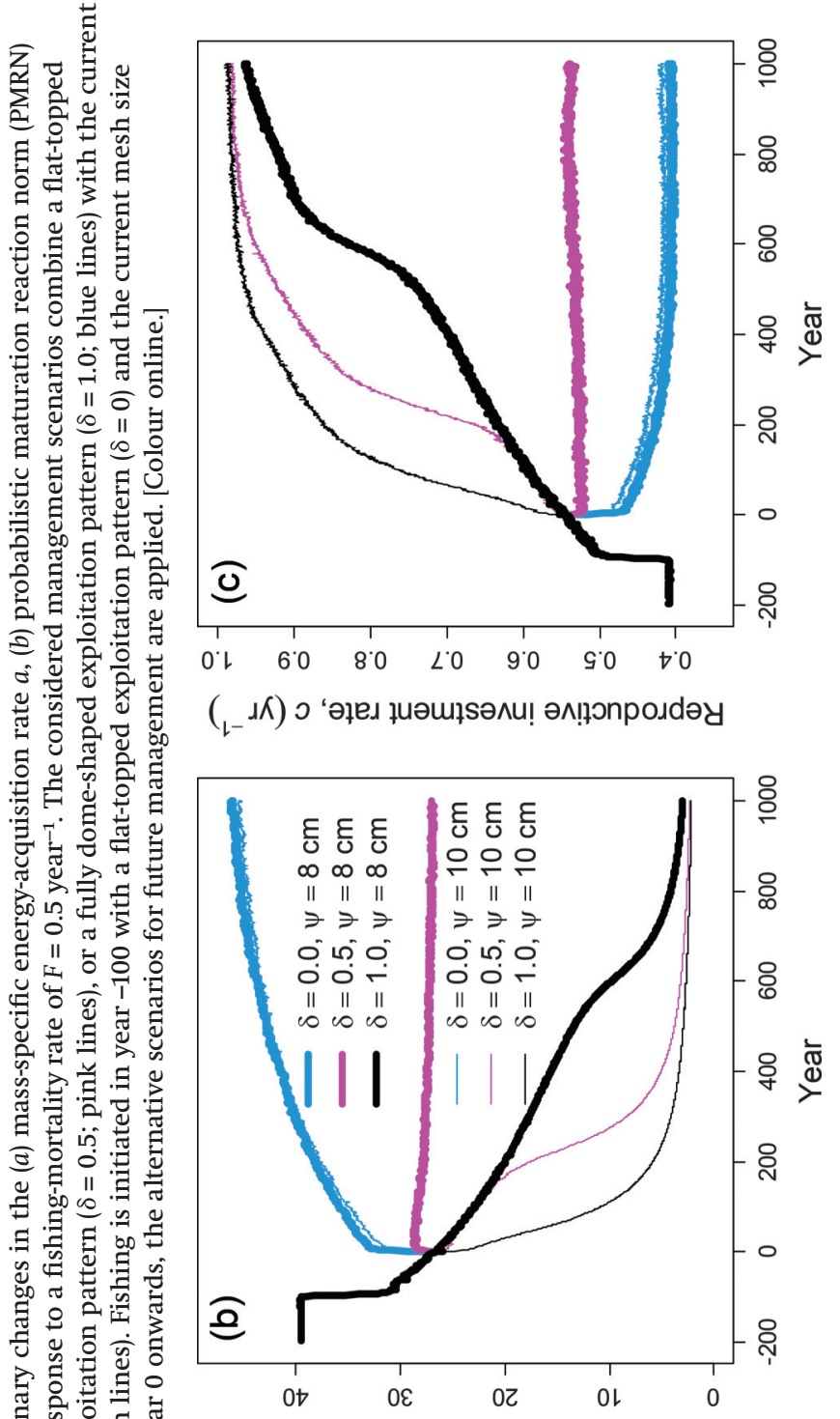

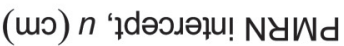

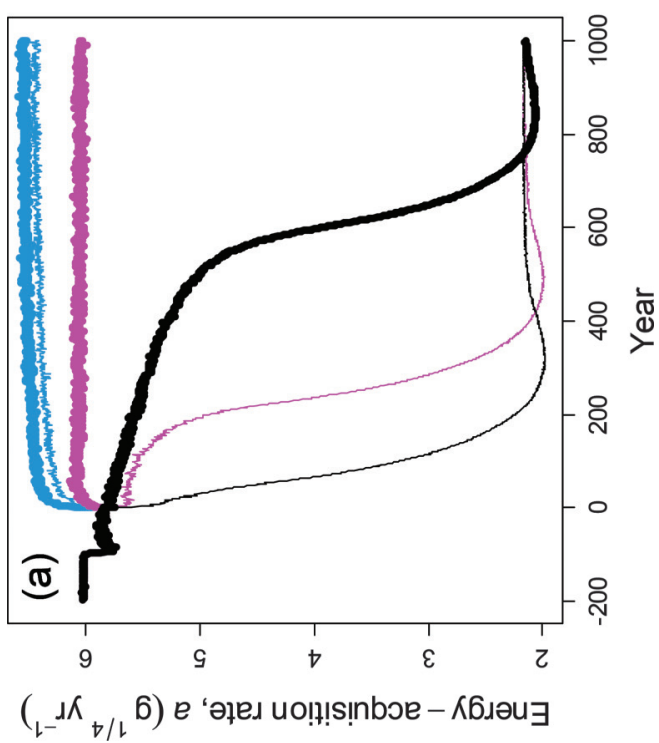




\section{Pagination not final (cite DOI) / Pagination provisoire (citer le DOI)}

Fig. 3. Evolution of yield and evolutionary impact expected under future management. Yields are expressed relative to the yield of the statusquo scenario in year $0\left(F=0.5\right.$ year $^{-1}, \psi=8 \mathrm{~cm}$, and $\left.\delta=0\right)$. (a) Evolution of yield over 1000 years. (b) Evolution of yield during the first 50 years. (c) Evolutionary impact during the first 50 years. The considered management scenarios use the current mesh size $(\psi=8 \mathrm{~cm})$ and combine a flat-topped exploitation pattern ( $\delta=0$; black lines), a partially dome-shaped exploitation pattern ( $\delta=0.5$; pink lines), or a fully dome-shaped exploitation pattern $\left(\delta=1.0\right.$; blue lines) with the current fishing-mortality rate ( $F=0.5$ year $^{-1}$; continuous lines) or the reference fishingmortality rate currently used by ICES ( $F=0.3$ year $^{-1}$; dashed lines). Results are compared with the scenario providing the maximum long-term yield $\left(F=0.12\right.$ year $^{-1}, \psi=12 \mathrm{~cm}$, and $\delta=0.5$; yellow dotted lines); see Table 1. [Colour online.]

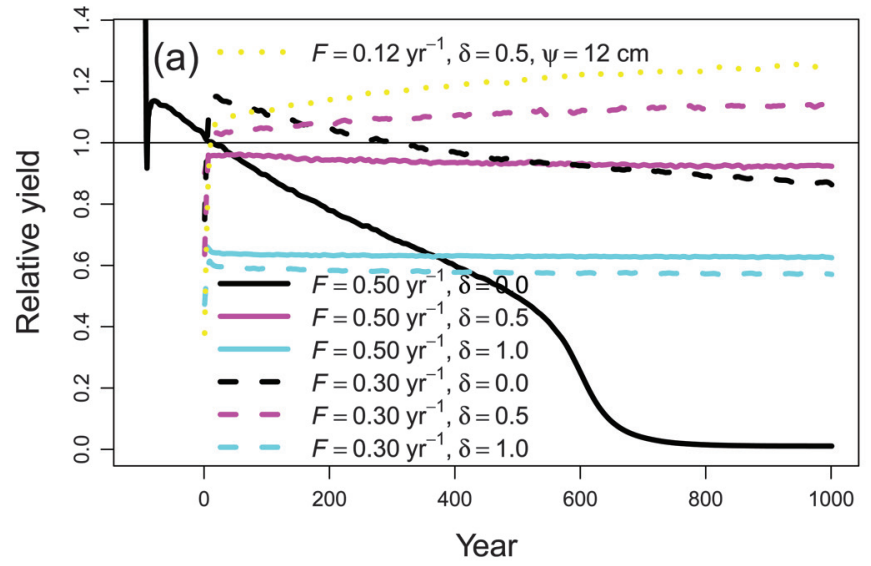

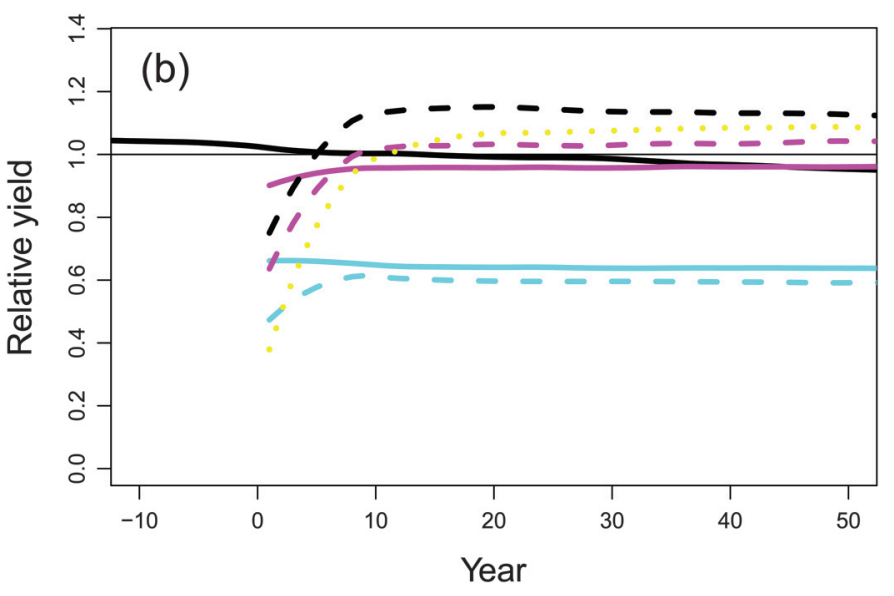

The evolution to dwarfism happens because of the increase in the maximum exploitation rate required to maintain fishing mortality at $F=0.5$ year $^{-1}$ given that an increasing proportion of the population does not grow beyond the retention size of the trawls (see below).

We find that management scenarios crucially affect the evolution of life-history traits. When a larger mesh size is used, the shift to dwarfism occurs even earlier, whereas a dome-shaped exploitation pattern may reverse the initial evolutionary response (Fig. 2). For a fully dome-shaped exploitation pattern $(\delta=1)$, the mass-specific energy-acquisition rate $a$ and the PMRN intercept evolve to slightly higher levels, and the mass-specific reproductiveinvestment rate $c$ recovers to a similar level as in the unexploited population. This strong recovery of initial trait values is due to selection for faster growth that reduces the time fish spent in the size range in which they are vulnerable to fishing. Under a domeshaped exploitation pattern, increasing the mesh size has only marginal effects on results. As the dome-shaped exploitation pattern imposes peak mortalities on intermediately sized fish, the occurrence of disruptive selection might be conjectured; however, this is not the case, and trait distributions remain unimodal (not shown).

To compensate for the gradual changes in the size distribution of the stock, the exploitation level $F_{\max }$ has to be increased so as to maintain the target fishing-mortality rate F. For a dome-shaped

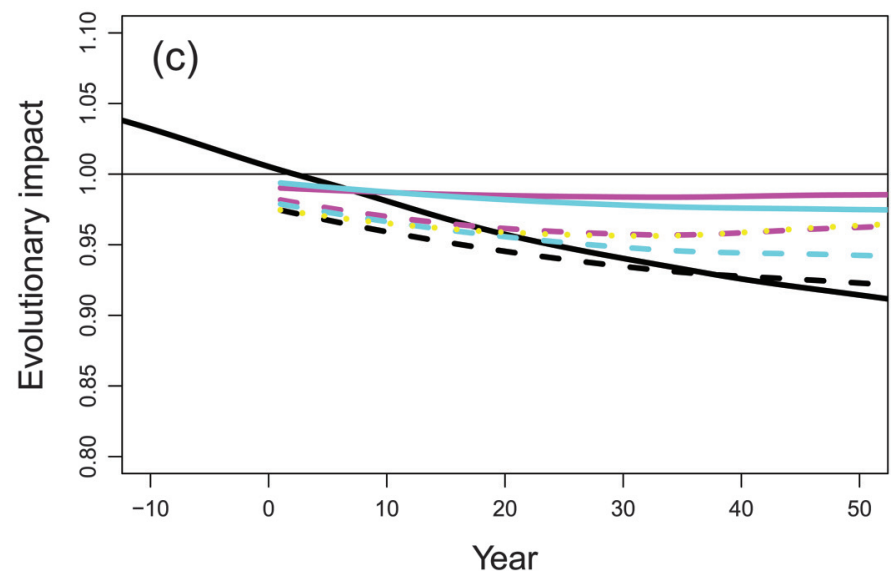

exploitation pattern $(\delta=1), F$ can be maintained over time without needing to raise $F_{\text {max }}$. In contrast, for a flat-topped exploitation pattern $(\delta=0), F_{\max }$ rises and exceeds 2.0 year $^{-1}$ within 400 years (not shown). If instead $F_{\text {max }}$ were fixed, the gradual changes in the size distribution towards smaller size would result in a decrease of $F$, which would slow down the rate of further evolutionary change.

\section{Evolutionary impact assessment}

The comparison of the time trends in yields under different management scenarios forms the basis of the evolutionary impact assessment that provides insight into the evolutionary consequences of different management scenarios and into the trade-off between short-term losses and long-term gains.

Under status-quo management $\left(F=0.5\right.$ year $^{-1}, \delta=0$, and $\psi=$ $8 \mathrm{~cm}$ ), yield gradually declines and falls to very low levels after about 500-600 years, coinciding with the evolution of dwarfism (Fig. 3a). A reduction of fishing mortality to the reference level currently used by ICES $\left(F=0.3\right.$ year $\left.^{-1}\right)$ prevents the evolution of dwarfism, but does not prevent the decline in yield. Imposing a dome-shaped exploitation pattern, in contrast, results in a stable - or even increasing - yield. This scenario shows a shortterm loss in yield during a period of about 10 years when compared with the status-quo scenario or the $F=0.3$ year $^{-1}$ scenario 


\section{Pagination not final (cite DOI) / Pagination provisoire (citer le DOI)}

(Fig. 3b). A decrease in fishing mortality to $F=0.12$ year ${ }^{-1}$, combined with an increase in mesh size to $\psi=12 \mathrm{~cm}$ and the adoption of a partially dome-shaped exploitation pattern $(\delta=0.5)$, results in a gradual increase in yield, exceeding the yields of the other scenarios after 10-100 years. This scenario, however, comes at the cost of a substantial reduction in yield during the first couple of years. This initial decrease in yield is due to two effects: the loss of large fish in the catch after imposing the dome-shaped exploitation pattern and the slow recovery of the population biomass after the decrease in fishing mortality.

The difference between the estimated yields from the models with evolving and static straits, $Y_{\text {evol }}$ and $Y_{\text {static }}$, respectively, quantifies the change in yield due to evolution (Fig. 3c). This difference is already apparent during the first few decades and becomes more pronounced when a longer time period is considered. For $F=0.5$ year $^{-1}, Y_{\text {evol }}$ after 50 years is $8 \%$ smaller than $Y_{\text {static }}$ and $100 \%$ smaller with the shift to dwarfism after 600 years. For $F=$ 0.3 year $^{-1}$, the relative loss in yield is smaller, reaching about $7 \%$ after 50 years and $30 \%$ at evolutionary equilibrium. Under a partially dome-shaped exploitation pattern $(\delta=0.5)$, the decrease in yield amounts to less than 5\% (Fig. 3c).

\section{Management reference points}

To estimate management reference points for fishing mortalities $F_{\mathrm{MY}}$ that generate maximum yield, we consider the yield curves after 10, 100, and 1000 years of evolution (Fig. 4). For a flat-topped exploitation pattern $(\delta=0)$ and a mesh size of $\psi=8 \mathrm{~cm}$, FIE results in a decrease from $F_{M Y}=0.26$ year $^{-1}$ in year 10 to $F_{M Y}=0.19$ year $^{-1}$ in year 100 and $F_{M Y}=0.14$ year $^{-1}$ at evolutionary equilibrium, while the relative MY remains at a level of about 1.15. Increasing mesh size to $\psi=10 \mathrm{~cm}$ gives a slightly higher MY at similar $F_{M Y}$, but the fishing-mortality rate $F$ at which yield crashes is reduced because of intensified selection (Fig. 4).

In contrast, a dome-shaped exploitation pattern may reverse the evolutionary trends and results in a stable yield over a broad range of fishing-mortality rates. Under a dome-shaped exploitation pattern, yield crashes only at extremely high fishing-mortality rates $\left(F>1\right.$ year $\left.^{-1}\right)$, because fish can no longer outgrow the size range in which they are vulnerable to fishing (not shown). FIE shifts $\mathrm{F}_{\mathrm{MY}}$ towards higher values, whereas the corresponding MY changes only marginally. The MY under dome-shaped exploitation patterns tends to be lower than under a flat-topped exploitation pattern owing to the fishery's selection of fish of intermediate size instead of large size.

The MY and associated $F_{M Y}$ after 1000 years of fishing can be considered evolutionarily sustainable, since life-history traits are close to stable. MY are highest for intermediate dome shapes $(0.25 \leq \delta \leq 0.75$; Table 1$)$, as part of the large fish are caught to maximize yield while the other part is protected to conserve the trait values resulting in large sizes. Under the premise that some large fish are conserved, yield is maximized for large mesh sizes, because the selection of large fish is then stronger within the size range of available fish. Our model suggests that the maximum evolutionarily sustainable yield is obtained for a fishing-mortality rate of $F=0.12$ year $^{-1}$, a partially dome-shaped exploitation pattern $(\delta=0.5)$, and a mesh size of $\psi=12 \mathrm{~cm}$ (Table 1). The corresponding MSY is $12 \%$ smaller than that for the model with static traits, which occurs for $F=0.25$ year $^{-1}, \delta=0$, and $\psi=12 \mathrm{~cm}$.

\section{Discussion}

Our results indicate that the fishing of North Sea plaice over the last 100 years has resulted in evolutionary changes in life-history traits that negatively affect the stock's yield. Continuation of this fishing regime will further erode the yield. This is predicted to happen on a decadal time scale and must therefore be considered relevant for contemporary fisheries management. Moreover, our study suggests that if this fishing regime is continued on a longer
Fig. 4. Evolution of the yield curve expected under future management after 10, 100, and 1000 years. Yields are expressed relative to the yield of the status-quo scenario in year $0(\mathrm{~F}=$ 0.5 year $^{-1}, \psi=8 \mathrm{~cm}$, and $\delta=0$ ). The considered management scenarios combine a flat-topped exploitation pattern $(\delta=0$; black lines), a partially dome-shaped exploitation pattern $(\delta=0.5$; pink lines), or a fully dome-shaped exploitation pattern $(\delta=1$; blue lines) with the current mesh size ( $\psi=8 \mathrm{~cm}$; thick lines) or a larger mesh size $(\psi=10 \mathrm{~cm}$; thin lines). Vertical and horizontal arrows show the changes in $F_{M Y}$ reference points after 100 and 1000 years of exploitation with a flat-topped exploitation pattern (on the left) and a fully dome-shaped exploitation pattern (on the right). [Colour online.]
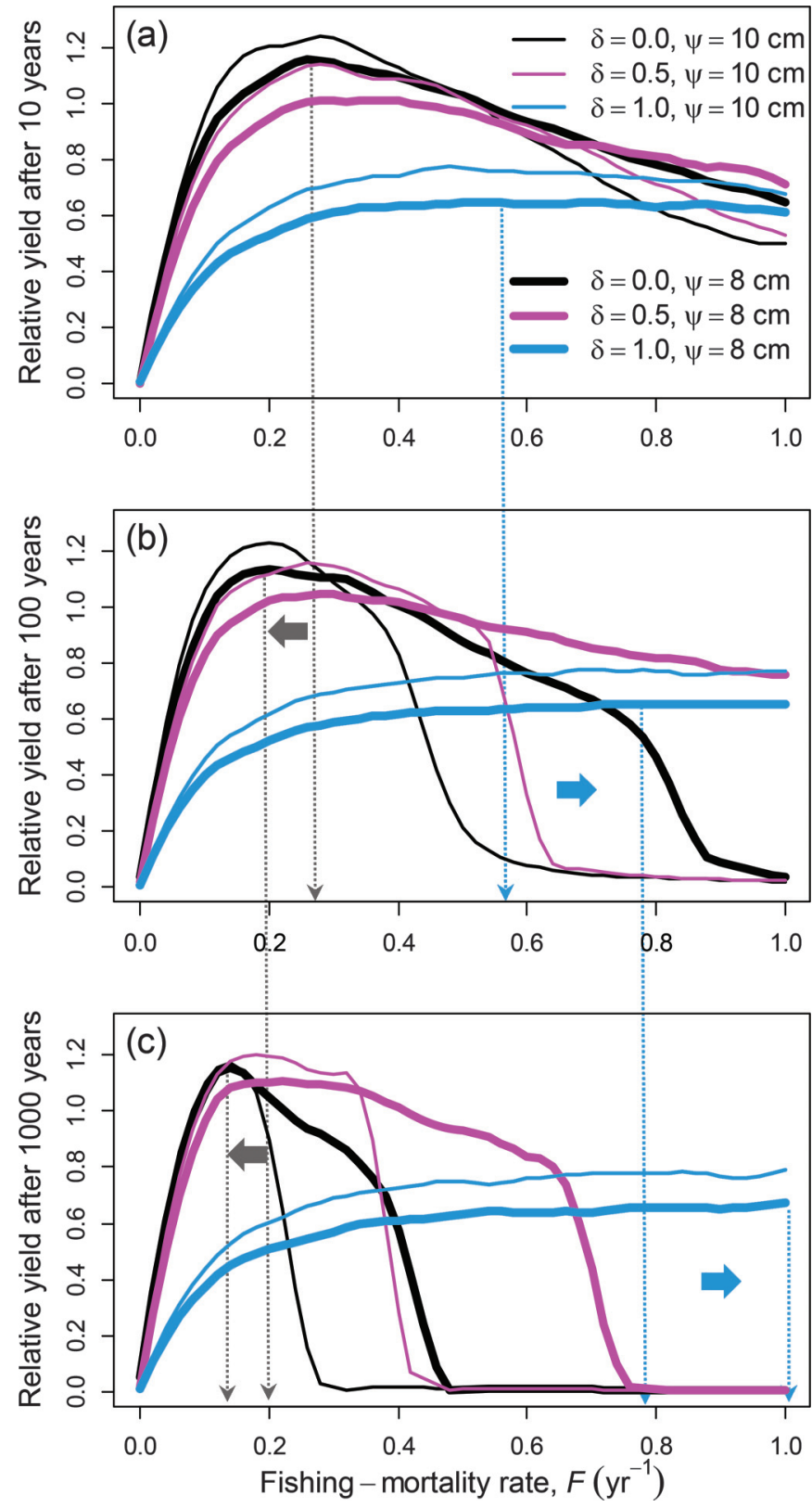

time scale, the population will further evolve and may reach a state of dwarfism. This will not only have severe consequences for the stock's yield, but will also impact trophic interactions and other aspects of the functioning of the North Sea ecosystem (Garcia et al. 2012; Andersen and Beyer 2015; Audzijonyte et al. 2013). 
Table 1. Maximum yields and corresponding fishing-mortality rates $\mathrm{F}_{\mathrm{MY}}$ for different combinations of relative availability $(\delta=0,0.25,0.5$, $0.75,1)$ and mesh size $(\psi=4,6,8,10,12 \mathrm{~cm})$ in the model with evolving traits (on the left) and in the model with static traits (on the right).

\begin{tabular}{|c|c|c|c|c|c|c|c|c|c|c|}
\hline \multirow{3}{*}{$\begin{array}{l}\text { Mesh } \\
\text { size }(\mathrm{cm})\end{array}$} & \multicolumn{5}{|c|}{ Evolving traits } & \multicolumn{5}{|c|}{ Static traits } \\
\hline & \multicolumn{5}{|c|}{ Relative availability } & \multicolumn{5}{|c|}{ Relative availability } \\
\hline & 0.00 & 0.25 & 0.50 & 0.75 & 1.00 & 0.00 & 0.25 & 0.50 & 0.75 & 1.00 \\
\hline \multicolumn{11}{|c|}{ Fishing-mortality rate at maximum yield (year-1) } \\
\hline 4 & 0.18 & 0.21 & 0.27 & 0.27 & 0.93 & 0.27 & 0.29 & 0.27 & 0.37 & 0.55 \\
\hline 6 & .15 & 0.21 & 0.30 & 0.42 & 0.93 & 0.26 & 0.25 & 0.31 & 0.41 & 0.49 \\
\hline U & 0.12 & 0.15 & 0.21 & 0.30 & 0.99 & 0.22 & 0.22 & 0.25 & 0.35 & 0.40 \\
\hline 10 & 15 & 0.15 & 0.21 & 0.30 & 0.87 & 0.26 & 0.29 & 0.24 & 0.25 & 0.42 \\
\hline 12 & 0.09 & 0.12 & 0.12 & 0.24 & 0.66 & 0.25 & 0.25 & 0.24 & 0.32 & 0.43 \\
\hline \multicolumn{11}{|c|}{ Relative maximum yield } \\
\hline 4 & 0.74 & 0.72 & 0.70 & 0.62 & 0.38 & 0.78 & 0.73 & 0.67 & 0.57 & 0.37 \\
\hline 6 & 0.75 & 0.74 & 0.74 & 0.65 & 0.40 & 0.82 & 0.77 & 0.69 & 0.61 & 0.40 \\
\hline 8 & 0.80 & 0.79 & 0.77 & 0.70 & 0.46 & 0.85 & 0.82 & 0.75 & 0.65 & 0.46 \\
\hline 10 & 0.80 & 0.84 & 0.83 & 0.81 & 0.54 & 0.93 & 0.88 & 0.83 & 0.74 & 0.54 \\
\hline 12 & 0.66 & 0.84 & 0.88 & 0.87 & 0.65 & 1.00 & 0.97 & 0.92 & 0.83 & 0.65 \\
\hline
\end{tabular}

\section{Dwarfism evolution}

The dwarfism predicted by the model under continuation of fishing using the flat-topped exploitation pattern at a fishingmortality rate of $F=0.5$ year $^{-1}$, about five times the current level of natural mortality (Beverton 1964), may seem surprising for a large species with a reported maximum body size of $91 \mathrm{~cm}$ (Wheeler 1969). Yet, dwarfism, resulting from a small maximum body size and a small size at maturation, is not uncommon; it has been reported for many fish species in general (Parker 1992; Sonin et al. 2007; MacColl et al. 2013) and within the order of the Pleuronectiformes in particular. In the North Sea, for instance, females of scaldfish (Arnoglossus laterna) (Gibson and Ezzi 1980) and solenette (Buglossidium luteum) (Nottage and Perkins 1983) become sexually mature in their second or third year of life at a length of less than $10 \mathrm{~cm}$ and reach a maximum body size of only around $15 \mathrm{~cm}$.

In our model, the maximum exploitation level $F_{\max }$ is continually adjusted so as to maintain the population's fishing-mortality rate at a scenario's target level. As $F_{\max }$ is roughly proportional to fishing effort, it is conceivable that such maintenance ceases to be economically profitable before the stock's evolution reaches the state of dwarfism.

\section{Exploitation patterns}

Our results show that the adverse evolutionary effects of fishing can be mitigated, or even reversed, by reducing the fishingmortality rate, changing the exploitation pattern, or both. In particular, imposing a dome-shaped exploitation pattern is predicted to select for life-history traits that allow fish to grow quickly through the size range in which they are maximally exploited. To this end, fish can increase their growth rate, postpone their maturation, and (or) reduce their reproductive investment. Pronounced evolutionary implications of a dome-shaped exploitation pattern were also observed in model-based studies focusing on cod (Jørgensen et al. 2009). Previous model-based studies have shown that the recovery of life-history traits tends to be slow after the closure of a fishery (Law 2000; Enberg et al. 2009); especially when such recovery involves the evolution of delayed maturation, it may be sped up by imposing a dome-shaped exploitation pattern.

Predictions of how a dome-shaped exploitation pattern affects life-history evolution depend on stock-specific circumstances, such as growth rates and the dome's peak and width relative to the exploitable size range. In regard to growth evolution alone (Sinclair et al. 2002), it has been highlighted before that depending on such circumstances, a dome-shaped exploitation pattern can result in lower survival for slow-growing individuals (positive directional selection), lower survival for fast-growing individuals (negative directional selection), or lower survival for individuals with intermediate growth rates (disruptive selection).

Our results underscore the importance of conserving big, old, fat, fecund female fish (BOFFFFs; Birkeland and Dayton 2005; Hixon et al. 2014). These are not only contributing disproportionally to new year classes, but also to the conservation of life-history traits (Law 2007).

\section{Management implications}

In light of the fishery-induced changes in life-history traits observed in our model, estimates of MSY and $F_{\text {MSY }}$ that are based on the assumption of static life-history traits cannot be considered as sustainable reference points (Heino et al. 2013). Our study shows that it is instead necessary to consider evolutionary models over a time horizon allowing the considered population to approach an evolutionary equilibrium. If the chosen time horizon is shorter, the estimated reference points will again not represent evolutionarily sustainable reference points. In our study, life-history traits are evolving and the modelled population is close to its evolutionary equilibrium at the end of the investigated time period; therefore, the estimated $\mathrm{MY}$ and associated $\mathrm{F}_{\mathrm{MY}}$ can be considered as good proxies of the evolutionarily sustainable MSY and $\mathrm{F}_{\mathrm{MSY}}$ management reference points.

We have shown that reducing the rate and reversing the direction of FIE in North Sea plaice can efficiently be achieved by changing the shape of the exploitation pattern alongside a reduction in fishing pressure. The introduction of an evolutionarily informed management regime will lead to a short-term drop in yield compared with status-quo management. In contrast, under status-quo management, yield will fall below that of the evolutionarily informed management regime after some time because of the continual erosion of yield due to FIE.

These predictions put a spotlight on the question of how fishery managers can influence a fishery's exploitation pattern. Whereas gill nets are characterized by selecting only intermediate size classes, trawls show a sigmoid selection pattern (Sparre and Venema 1999; Kuparinen et al. 2009). Hence, replacing (part of) a trawl fishery with a gillnet fishery will change the resultant exploitation pattern from flat-topped to dome-shaped). A trawl fishery's exploitation pattern can be modified to become more dome-shaped also by varying the spatial distribution of fishing effort; this is possible if size classes differ in their spatial distribution and the fishery increasingly targets fishing grounds where the intermediate size classes dominate (Sampson and Scott 2012). For North Sea plaice, managers could thus protect the larger size classes by reducing fishing during the spawning period, when all adult size classes aggregate on the spawning grounds (Rijnsdorp et al. 2012; van Overzee and Rijnsdorp 2015).

\section{Model uncertainty}

Although our model is calibrated for North Sea plaice females and their life-history traits during the 20th century (Mollet 2010), the resultant predictions have to be interpreted with care, as they are conditional on the processes included in the model and on the assumptions made for the calibration.

An important simplification of our analysis is that we only consider females. North Sea plaice is a sexual dimorphic species in which males mature at a younger age and smaller size than females and subsequently also grow to a smaller maximum size. As the fishery's selectivity is higher for males than for females (Rijnsdorp 1993b), it may be even stronger in reality than assumed in our model. 


\section{Pagination not final (cite DOI) / Pagination provisoire (citer le DOI)}

Can. J. Fish. Aquat. Sci. Vol. 73, 2016

In the parameter-rich ecogenetic model we use, different parameter combinations, especially in the growth-survival trade-off and the reproduction-survival trade-off, may result in similarly good fits with observations. Our model calibration assumes a similar steepness in these two life-history trade-offs. Although this steepness affects the speed of evolution, in particular of the traits for energy acquisition and reproductive investment, this effect will be compensated by the adjustment of the coefficients of variation of the evolving traits. As a result, the direction of evolution towards the model's evolutionary equilibria remains the same for different assumptions about the steepness of the life-history trade-offs.

We further assume that during the 20th century, North Sea plaice was fished at a constant fishing-mortality rate of $F=$ 0.5 year $^{-1}$, with a flat-topped exploitation pattern, and under constant environmental conditions. While these simplifications provide a reasonable summary of the stock's fishing history, the real situation has of course been more complex. First, Rijnsdorp and Millner (1996), who reviewed the historic literature and reanalysed the available historical data, showed that fishing mortality varied between $F=0.4$ and 0.9 year $^{-1}$ during the 20th century and virtually ceased during the first and second world wars. Second, the highest fishing mortalities occurred for intermediate size classes. Third, the growth rate of North Sea plaice has not been constant during the 20th century, due to changes in eutrophication, temperature, and density-dependent control on the crowded nursery grounds (Rijnsdorp and van Leeuwen 1996; Teal et al. 2008).

We model recruitment using a Beverton-Holt stock-recruitment relationship, with parameters that render recruitment independent of population biomass for a broad range of population biomasses. The stock-recruitment relationship, however, may also be affected by FIE. Heino et al. (2013) argued that FIE may increase a population's growth rate in recruitment-regulated populations such as plaice. Using a model parameterized for Atlantic cod (Gadus morhua), Kuparinen et al. (2014) suggested that FIE may influence the production of recruits and the recruit-per-spawner ratio. The extent to which such evolution affects yield depends on the density-dependent processes that regulate population biomass. In plaice, population regulation occurs during the early life stages, in particular when the pelagic larvae settle in the localized nursery areas (van der Veer et al. 2000). A change in energy acquisition has a direct effect on growth rates after settlement. How this in turn affects survival is difficult to predict and largely depends on the specific ecological conditions regarding food and predators during this vulnerable stage.

The simplifications discussed above underscore that our modelbased predictions must be interpreted with sufficient caution. Eventually, it would be desirable to carry out robustness checks and sensitivity analyses in regard to all mentioned potential complications. Since it has been our goal here to arrive at general predictions for comparing the evolutionary impacts of flattopped and dome-shaped exploitation patterns and of low and high fishing-mortality rates, and since the used ecogenetic model is already complex enough, we think that these simplifications are justified and that the direction of evolutionary responses, as well as the difference between the explored management scenarios, will be robust to such further complications. This conclusion is supported by the similarity in evolutionary responses predicted by our model and model-based studies of other species (Dunlop et al. 2009; Enberg et al. 2009; Jørgensen et al. 2009; Eikeset et al. 2013).

\section{Evolutionary impact assessment}

The current management objective for North Sea plaice is to reduce fishing mortality to $F=0.3$ year ${ }^{-1}$ (Council Regulation (EC) No. 676/2007). Our results show that even at this level of fishing, a substantial part of future yield may be lost to evolutionary effects.
If large fish remain unprotected, the resultant long-term evolutionary loss in yield will eventually exceed the short-term gain. Our model shows that this break-even point occurs $10-40$ years into the future, depending on management scenarios (Fig. 3b). The maximum evolutionarily sustainable yield is estimated to occur at a fishing-mortality rate of $F=0.12$ year $^{-1}$, a mesh size of $\psi=12 \mathrm{~cm}$, and a partially dome-shaped exploitation pattern $(\delta=0.5)$. This yield is only slightly less than the maximum yield estimated for the model with static life-history traits, which occurs at a higher fishing mortality and for a flat-topped exploitation pattern (Table 1).

Managing North Sea plaice to achieve the maximum evolutionarily sustainable yield would imply a substantial loss in yield during the first 10 years following the management change. Furthermore, this short-term loss would be augmented by losses in the catch of sole (Solea solea). As plaice is caught in a mixed fishery for flatfish including sole, turbot (Scophthalmus maximus), and brill (Scophthalmus rhombus) (Daan 1997; Gillis et al. 2008), an increase in mesh size to 10 or $12 \mathrm{~cm}$ would result in a substantial loss in yield of the slender sole. Managing this flatfish fishery will therefore need to trade off the effects of potential management measures across all target species.

In this study, we did not quantify the economic notion that current yield is more valuable than future yield. Economists apply discount rates when comparing current and future costs and benefits (Eikeset et al. 2013; Zimmerman and Jørgensen 2015). On the decadal time scale on which the benefits of evolutionarily informed management accrue, even low discount rates have a major influence on the economic assessment. From a conservation point of view, however, one may argue that the possibilities for future generations to harvest a fish stock should not be discounted against present yield (Laugen et al. 2014). While the millennial time frame we have used to study evolutionary equilibration is not proposed to be relevant for contemporary fisheries management, the multidecadal time frame over which FIE affects yield is comparable to that of other processes affecting stock productivity, such as climate change (Blanchard et al. 2012).

The ecosystem approach to fisheries management requires accounting for a fishery's adverse ecosystem impacts in managementstrategy evaluations (Caddy 1999; Rice 2011). When evaluating costs and benefits of the reduction in fishing effort required to mitigate FIE, it is therefore important to keep in mind that such a reduction will certainly contribute to diminishing other adverse effects of fishing, such as discarding and disturbance of the sea bed and benthic ecosystem. How the changes in exploitation pattern required to mitigate FIE affect other ecosystem services is less easy to predict and will benefit from future study.

In a next step, evolutionary impact assessments need to be carried out for the other species targeted by the North Sea flatfish fishery. Species-specific insights should then be combined in an integrative assessment, including the fishery's ecosystem effects, as explored by Rijnsdorp et al. (2012). Our study already highlights the multiple benefits of a spawning closure for North Sea plaice, which combines positive effects on the plaice stock and the fishery's revenue with reductions of negative effects regarding FIE and several other ecosystem indicators. Tailored solutions need to be developed in consultation with stakeholders to trade off the salient ecological and economic objectives.

\section{Acknowledgements}

Author contributions: conceived and designed the study and model: FM, UD, ADR, JJP; built the model: FM; calibrated the model: FM, ADR; wrote the paper: FM, ADR, JJP, UD. This research has been supported by the European Marie Curie Research Training Network on Fisheries-induced Adaptive Changes in Exploited Stocks (FishACE; contract MRTN-CT-2204-005578) and by the European Specific Targeted Research Programme on Fisheriesinduced Evolution (FinE; contract SSP-2006-044276), funded through the European Community's Sixth Framework Programme. 
The paper does not necessarily reflect the views of the European Commission and does not anticipate the Commission's future policy in this area. The authors gratefully acknowledge additional financial support by the Strategic Research Program on Sustainable Spatial Development of Ecosystems, Landscapes, Seas and Regions funded by the Dutch Ministry of Agriculture, Nature Conservation and Food Quality (JJP, ADR), as well as by the European Science Foundation (UD), the Austrian Science Fund (FWF; UD), the Austrian Ministry of Science and Research (BMWF; UD), and the Vienna Science and Technology Fund (WWTF; UD).

\section{References}

Andersen, K.H., and Beyer, J.E. 2015. Size structure, not metabolic scaling rules, determines fisheries reference points. Fish Fish. 16(1): 1-22. doi:10.1111/faf. 12042.

Audzijonyte, A., Kuparinen, A., Gorton, R., and Fulton, E.A. 2013. Ecological consequences of body size decline in harvested fish species: positive feedback loops in trophic interactions amplify human impact. Biol. Lett. 9(2): 20121103. doi:10.1098/rsbl.2012.1103.

Beverton, R.J.H. 1964. Differential catchability of male and female plaice in the North Sea and its effect on estimates of stock abundance. Rapp. Proc.-V. Reun. Cons. Int. Explor. Mer, 155: 103-112.

Beverton, R.J.H., and Holt, S.J. 1957. On the dynamics of exploited fish populations. Fisheries Investigations, Series II. Vol. XIX. Ministry of Agriculture, Fisheries and Food, London.

Birkeland, C., and Dayton, P. 2005. The importance in fishery management of leaving the big ones. Trends Ecol. Evol. 20: 356-358. doi:10.1016/j.tree.2005. 03.015.

Blanchard, J.L., Jennings, S., Holmes, R., Harle, J., Merino, G., Allen, J.I., Holt, J., Dulvy, N.K., and Barange, M. 2012. Potential consequences of climate change for primary production and fish production in large marine ecosystems. Philos. Trans. R. Soc. B Biol. Sci. 367(1605): 2979-2989. doi:10.1098/rstb.2012. 0231.

Caddy, J.F. 1999. Fisheries management in the twenty-first century: will new paradigms apply? Rev. Fish Biol. Fish. 9(1): 1-43. doi:10.1023/A:1008829909601.

Caddy, J.F., and Mahon, R. 1995. Reference points for fisheries management. FAO Fisheries Technical Paper 347. FAO, Rome, Italy.

Conover, D.O. 2000. Darwinian fisheries science. Mar. Ecol. Progr. Ser. 208: 303-307.

Conover, D.O., and Munch, S.B. 2002. Sustaining fisheries yields over evolutionary time scales. Science, 297(5578): 94-96. doi:10.1126/science.1074085.

Daan, N. 1997. TAC management in North Sea flatfish fisheries. J. Sea Res. 37: 321-341. doi:10.1016/S1385-1101(97)00026-9.

Dieckmann, U., Heino, M., and Rijnsdorp, A.D. 2009. The dawn of Darwinian fishery management. ICES Insight, 46: 34-43.

Dunlop, E.S., Heino, M., and Dieckmann, U. 2009. Eco-genetic modeling of contemporary life-history evolution. Ecol. Appl. 19(7): 1815-1834. doi:10.1890/081404.1.

Eikeset, A.M., Richter, A., Dunlop, E.S., Dieckmann, U., and Stenseth, N.C. 2013. Economic repercussions of fisheries-induced evolution. Proc. Natl. Acad. Sci. U.S.A. 110(30): 12259-12264. doi:10.1073/pnas.1212593110.

Enberg, K., Jørgensen, C., Dunlop, E.S., Heino, M., and Dieckmann, U. 2009. Implications of fisheries-induced evolution for stock rebuilding and recovery. Evol. Appl. 2(3): 394-414. doi:10.1111/j.1752-4571.2009.00077.x.

Garcia, S.M., Kolding, J., Rice, J., Rochet, M.-J., Zhou, S., Arimoto, T., Beyer, J.E., Borges, L., Bundy, A., Dunn, D., Fulton, E.A., Hall, M., Heino, M., Law, R., Makino, M., Rijnsdorp, A.D., Simard, F., and Smith, A.D.M. 2012. Reconsidering the consequences of selective fisheries. Science, 335(6072): 1045-1047. doi:10.1126/science.1214594.

Gibson, R.N., and Ezzi, I.A. 1980. The biology of the scaldfish, Arnoglossus laterna (Walbaum) on the west coast of Scotland. J. Fish Biol. 17: 565-575. doi:10.1111/ j.1095-8649.1980.tb02788.x.

Gillis, D.M., Rijnsdorp, A.D., and Poos, J.J. 2008. Behavioral inferences from the statistical distribution of commercial catch: patterns of targeting in the landings of the Dutch beam trawler fleet. Can. J. Fish. Aquat. Sci. 65(1): 27-37. doi:10.1139/f07-147.

Grift, R.E., Rijnsdorp, A.D., Barot, S., Heino, M., and Dieckmann, U. 2003. Fisheries-induced trends in reaction norms for maturation in North Sea plaice. Mar. Ecol. Prog. Ser. 257: 247-257. doi:10.3354/meps257247.

Heino, M. 1998. Management of evolving fish stocks. Can. J. Fish. Aquat. Sci. 55(8): 1971-1982. doi:10.1139/f98-089.

Heino, M., Dieckmann, U., and Godø, O.R. 2002. Measuring probabilistic reaction norms for age and size at maturation. Evolution, 56(4): 669-678. doi:10. 1111/j.0014-3820.2002.tb01378.x.

Heino, M., Baulier, L., Boukal, D.S., Ernande, B., Johnston, F.D., Mollet, F.M., Pardoe, H., Therkildsen, N.O., Uusi-Heikkilä, S., Vainikka, A., Arlinghaus, R., Dankel, D.J., Dunlop, E.S., Eikeset, A.M., Enberg, K., Engelhard, G.H., Jørgensen, C., Laugen, A.T., Matsumura, S., Nusslé, S., Urbach, D., Whitlock, R., Rijnsdorp, A.D., and Dieckmann, U. 2013. Can fisheries-induced evolution shift reference points for fisheries management? ICES J. Mar. Sci. 70(4): 707-721. doi:10.1093/icesjms/fst077.

Hilborn, R., and Walters, C.J. 1992. Quantitative fisheries stock assessment. Chapman \& Hall, London.

Hixon, M.A., Johnson, D.W., and Sogard, S.M. 2014. BOFFFFs: on the importance of conserving old-growth age structure in fishery populations. ICES J. Mar. Sci. 71: 2171-2185. doi:10.1093/icesjms/fst200.

Hutchings, J.A. 2009. Avoidance of fisheries-induced evolution: management implications for catch selectivity and limit reference points. Evol. Appl. 2(3): 324-334. doi:10.1111/j.1752-4571.2009.00085.x.

ICES. 2011. Report of the ICES Advisory Committee, 2011. ICES Advice, 2011. Books 1-11.

ICES. 2014. Report of the ICES Advisory Committee, 2014. ICES Advice, 2014. Books 1-11.

Jørgensen, C., Enberg, K., Dunlop, E.S., Arlinghaus, R., Boukal, D.S., Brander, K., Ernande, B., Gardmark, A., Johnston, F., Matsumura, S., Pardoe, H., Raab, K., Silva, A., Vainikka, A., Dieckmann, U., Heino, M., and Rijnsdorp, A.D. 2007. Managing evolving fish stocks. Science, 318: 1247-1248. doi:10.1126/science. 1148089.

Jørgensen, C., Ernande, B., and Fiksen, O. 2009. Size-selective fishing gear and life history evolution in the Northeast Arctic cod. Evol. Appl. 2(3): 356-370. doi:10.1111/j.1752-4571.2009.00075.x.

Kuparinen, A., and Merilä, J. 2007. Detecting and managing fisheries-induced evolution. Trends Ecol. Evol. 22: 652-659. doi:10.1016/j.tree.2007.08.011.

Kuparinen, A., Kuikka, S., and Merilä, J. 2009. Estimating fisheries-induced selection: traditional gear selectivity research meets fisheries-induced evolution. Evol. Appl. 2(2): 234-243. doi:10.1111/j.1752-4571.2009.00070.x.

Kuparinen, A., Stenseth, N.C., and Hutchings, J.A. 2014. Fundamental populationproductivity relationships can be modified through density-dependent feedbacks of life-history evolution. Evol. Appl. 7(10): 1218-1225. doi:10.1111/eva. 12217.

Larkin, P.A. 1977. An epitaph for the concept of maximum sustained yield. Trans. Am. Fish. Soc. 106(1): 1-11. doi:10.1577/1548-8659(1977)106\%3C1:AEFTCO\%3E2. $0 . \mathrm{CO} ; 2$.

Laugen, A.T., Engelhard, G.H., Whitlock, R., Arlinghaus, R., Dankel, D.J., Dunlop, E.S., Eikeset, A.M., Enberg, K., Jørgensen, C., Matsumura, S., Nusslé, S., Urbach, D., Baulier, L., Boukal, D.S., Ernande, B., Johnston, F.D., Mollet, F., Pardoe, H., Therkildsen, N.O., Uusi-Heikkilä, S., Vainikka, A., Heino, M., Rijnsdorp, A.D., and Dieckmann, U. 2014. Evolutionary impact assessment: accounting for evolutionary consequences of fishing in an ecosystem approach to fisheries management. Fish Fish. 15(1): 65-96. doi:10.1111/ faf.12007.

Law, R. 2000. Fishing, selection, and phenotypic evolution. ICES J. Mar. Sci. 57: 659-668. doi:10.1006/jmsc.2000.0731.

Law, R. 2007. Fisheries-induced evolution: present status and future directions. Mar. Ecol. Prog. Ser. 335: 271-277. doi:10.3354/meps335271.

Law, R., and Grey, D.R. 1989. Evolution of yields from populations with agespecific cropping. Evol. Ecol. 3(4): 343-359. doi:10.1007/BF02285264.

MacColl, A.D.C., Nagar, A.E., and de Roij, J. 2013. The evolutionary ecology of dwarfism in three-spined sticklebacks. J. Anim. Ecol. 82: 642-652. doi:10.1111/ 1365-2656.12028.

Mollet, F.M. 2010. Evolutionary effects of fishing and implications for sustainable management: a case study of North Seas plaice and sole. Ph.D. thesis, Wageningen University.

Mollet, F.M., Dieckmann, U., and Rijnsdorp, A.D. 2015. Reconstructing the effects of fishing on life history evolution in North Sea plaice (Pleuronectes platessa). Mar. Ecol. Prog. Ser. doi:10.3354/meps11441.

Nottage, A.S., and Perkins, E.J. 1983. The biology of solenette, Buglossidium luteum (Risso), in the Solway Firth. J. Fish Biol. 22: 21-27. doi:10.1111/j.1095-8649.1983. tb04722x.

Okamoto, K.W., Whitlock, R., Magnan, P., and Dieckmann, U. 2009. Mitigating fisheries-induced evolution in lacustrine brook charr (Salvelinus fontinalis) in southern Quebec, Canada. Evol. Appl. 2: 415-437. doi:10.1111/j.1752-4571.2009. 00095.x

Olsen, E.M., Heino, M., Lilly, G.R., Morgan, M.J., Brattey, J., Ernande, B., and Dieckmann, U. 2004. Maturation trends indicative of rapid evolution preceded the collapse of northern cod. Nature, 428: 932-935. doi:10.1038/ nature 02430 .

Parker, G.A. 1992. The evolution of sexual size dimorphism in fish. J. Fish Biol. 41: 1-20. doi:10.1111/j.1095-8649.1992.tb03864.x.

Reznick, D.A., Bryga, H., and Endler, J.A. 1990. Experimentally induced lifehistory evolution in a natural population. Nature, 346(6282): 357-359. doi: 10.1038/346357a0.

Rice, J. 2011. Managing fisheries well: delivering the promises of an ecosystem approach. Fish Fish. 12(2): 209-231. doi:10.1111/j.1467-2979.2011.00416.x.

Rijnsdorp, A.D. 1993a. Fisheries as a large-scale experiment on life-history evolution: disentangling phenotypic and genetic effects in changes in maturation and reproduction of North Sea plaice, Pleuronectes platessa L. Oecologia, 96: 391-401. doi:10.1007/BF00317510.

Rijnsdorp, A.D. 1993b. Selection differentials in male and female North Sea plaice and changes in maturation and fecundity. In The exploitation of evolving resources. Edited by T.K. Stokes, J.M. McGlade, and R. Law. SpringerVerlag, Berlin. pp. 19-36. 


\section{Pagination not final (cite DOI) / Pagination provisoire (citer le DOI)}

Rijnsdorp, A.D., and Millner, R.S. 1996. Trends in population dynamics and exploitation of North Sea plaice (Pleuronectes platessa L.) since the late 1800s. ICES J. Mar. Sci. 53(6): 1170-1184. doi:10.1006/jmsc.1996.0142.

Rijnsdorp, A.D., and van Leeuwen, P.I. 1996. Changes in growth of North Sea plaice since 1950 in relation to density, eutrophication, beam-trawl effort, and temperature. ICES J. Mar. Sci. 53(6): 1199-1213. doi:10.1006/jmsc.1996. 0145 .

Rijnsdorp, A.D., Grift, R.E., and Kraak, S.B.M. 2005. Fisheries-induced adaptive change in reproductive investment in North Sea plaice (Pleuronectes platessa)? Can. J. Fish. Aquat. Sci. 62(4): 833-843. doi:10.1139/f05-039.

Rijnsdorp, A.D., van Overzee, H.M.J., and Poos, J.J. 2012. Ecological and economic trade-offs in the management of mixed fisheries: a case study of spawning closures in flatfish fisheries. Mar. Ecol. Prog. Ser. 447: 179-194. doi:10.3354/ meps09519.

Roff, D.A. 1991. The evolution of life-history variation in fishes, with particular reference to flatfishes. Neth. J. Sea Res. 27(3-4): 197-207. doi:10.1016/00777579(91)90024-U.

Sampson, D.B., and Scott, R.D. 2012. An exploration of the shapes and stability of population-selection curves. Fish Fish. 13(1): 89-104. doi:10.1111/j.1467-2979. 2011.00417.x.

Sinclair, A.F., Swain, D.P., and Hanson, J.M. 2002. Measuring changes in the direction and magnitude of size-selective mortality in a commercial fish population. Can. J. Fish. Aquat. Sci. 59(2): 361-371. doi:10.1139/f02-015.

Sonin, O., Spanier, E., Levi, D., Patti, B., Rizzo, P., and Andreoli, M.G. 2007. Nanism (dwarfism) in fish: a comparison between red mullet Mullus barbatus from the southeastern and the central Mediterranean. Mar. Ecol. Prog. Ser. 343: 221-228. doi:10.3354/meps06917.

Sparre, P., and Venema, S. 1999. Introduction to tropical fish stock assessment Part 2: Exercises. FAO Fisheries Technical paper 306/2.

Stearns, S.C., and Koella, J.C. 1986. The evolution of phenotypic plasticity in life-history traits: predictions of reaction norms for age and size at maturity. Evolution, 40: 893-913. doi:10.2307/2408752.

Stokes, T.K., McGlade, J.M., and Law, R. 1993. The exploitation of evolving resources. Lecture Notes in Biomathematics 99, Springer-Verlag, Berlin.

Teal, L.R., de Leeuw, J.J., van der Veer, H.W., and Rijnsdorp, A.D. 2008. Effects of climate change on growth of 0-group sole and plaice. Mar. Ecol. Prog. Ser. 358: 219-230. doi:10.3354/meps07367.

Thériault, V., Dunlop, E.S., Dieckmann, U., Bernatchez, L., and Dodson, J.J. 2008. The impact of fishing-induced mortality on the evolution of alternative lifehistory tactics in brook charr. Evol. Appl. 1: 409-423. doi:10.1111/j.1752-4571. 2008.00022.X

United Nations. 2002. Plan of Implementation of the World Summit on Sustainable Development. UN Document A/CONF.199/20

van der Veer, H.W., Berghahn, R., Miller, J.M., and Rijnsdorp, A.D. 2000. Recruitment in flatfish, with special emphasis on North Atlantic species: progress made by the Flatfish Symposia. ICES J. Mar. Sci. 57: 202-215. doi:10.1006/jmsc. 1999.0523.

van Overzee, H.M.J., and Rijnsdorp, A.D. 2015. Effects of fishing during the spawning period: implications for sustainable management. Rev. Fish Biol. Fish. 25(1): 65-83. doi:10.1007/s11160-014-9370-X.

van Walraven, L., Mollet, F.M., van Damme, C.J.G., and Rijnsdorp, A.D. 2010. Fisheries-induced evolution in growth, maturation and reproductive investment of the sexually dimorphic North Sea plaice (Pleuronectes platessa L.). J. Sea Res. 64(1-2): 85-93. doi:10.1016/j.seares.2009.07.003.

van Wijk, S.J., Taylor, M.I., Creer, S., Dreyer, C., Rodrigues, F.M., Ramnarine, I.W., van Oosterhout, C., and Carvalho, G.R. 2013. Experimental harvesting of fish populations drives genetically based shifts in body size and maturation. Front. Ecol. Environ. 11(4): 181-187. doi:10.1890/120229.

West, G.B., Brown, J.H., and Enquist, B.J. 2001. A general model for ontogenetic growth. Nature, 413(6856): 628-631. doi:10.1038/35098076.

Wheeler, A. 1969. The Fishes of the British Isles and North-West Europe. Macmillan, London.

Zimmermann, F., and Jørgensen, C. 2015. Bioeconomic consequences of fishinginduced evolution: a model predicts limited impact on net present value. Can. J. Fish. Aquat. Sci. 72(4): 612-624. doi:10.1139/cjfas-2014-0006.

\section{Appendix A}

\section{Energy allocation}

According to eq. 1, an individual's somatic growth rate $\mathrm{d} w / \mathrm{d} t$ is given by the energy-acquisition rate $a w^{3 / 4}$ diminished by the maintenance rate $b w$ and, for adults, the reproductive-investment rate $c w$ (Fonds et al. 1992; West et al. 1997, 2001). Thus, reproduction is prioritized over growth. Furthermore, if the acquired energy cannot even cover the maintenance costs, the individual neither grows nor reproduces and instead experiences starvation mortality (see below).

\section{Growth}

From eq. 1, we obtain the annual growth increment by expressing the somatic mass $w_{t+1}$ at age $t+1$ as a function of the somatic
Table A1. Model variables of the ecogenetic model of female North Sea plaice, including individual traits and emergent characteristics.

\begin{tabular}{|c|c|c|}
\hline Symbol & Description & Unit \\
\hline \multicolumn{3}{|c|}{ Individual traits } \\
\hline$t$ & Age & year \\
\hline$w$ & Somatic mass & $\mathrm{g}$ \\
\hline$l$ & Body length & $\mathrm{cm}$ \\
\hline$a, a_{\mathrm{g}}$ & $\begin{array}{l}\text { Mass-specific (phenotypic, genetic) } \\
\text { energy-acquisition rate (evolving) }\end{array}$ & $\mathrm{g}^{1 / 4} \cdot$ year $^{-1}$ \\
\hline$c$ & $\begin{array}{l}\text { Mass-specific reproductive-investment } \\
\text { rate (evolving) }\end{array}$ & year $^{-1}$ \\
\hline$u$ & PMRN intercept (evolving) & $\mathrm{cm}$ \\
\hline \multicolumn{3}{|c|}{ Emergent characteristics } \\
\hline$p_{\text {mat }}(l, t)$ & Probability of maturation & - \\
\hline$l_{\mathrm{p} 50}(t)$ & Age-specific PMRN midpoint & $\mathrm{cm}$ \\
\hline$d$ & Interquartile PMRN width & $\mathrm{cm}$ \\
\hline$\gamma$ & Reproductive investment & $\mathrm{g}$ \\
\hline$\nu$ & Reproductive success & - \\
\hline$m_{\mathrm{p}}$ & Foraging-mortality rate & year $^{-1}$ \\
\hline$m_{\mathrm{r}}$ & Reproduction-mortality rate & year $^{-1}$ \\
\hline$m_{\mathrm{s}}$ & Starvation-mortality rate & year $^{-1}$ \\
\hline$M$ & Natural-mortality rate & year $^{-1}$ \\
\hline F & Fishing-mortality rate & year $^{-1}$ \\
\hline B & $\begin{array}{l}\text { Total biomass of individuals smaller } \\
\text { than } 25 \mathrm{~cm}\end{array}$ & $\mathrm{~g}$ \\
\hline$N_{\mathrm{r}}$ & No. of recruits & - \\
\hline
\end{tabular}

mass $w_{t}$ at age $t$ at the start of the growing season, taking into account that adult females do not feed during their spawning period of 6 weeks (or 0.125 years):

$$
\begin{aligned}
& w_{t+1}^{1 / 4}=\frac{a}{b}-\left(\frac{a}{b}-w_{t}^{1 / 4}\right) \exp (-b / 4) \quad \text { if juvenile } \\
& w_{t+1}^{1 / 4}=\frac{a}{b+c}-\left(\frac{a}{b+c}-w_{t}^{1 / 4}\right) \exp (-0.875[b+c] / 4) \quad \text { if adult }
\end{aligned}
$$

The annual reproductive investment $\gamma_{t+1}$ at age $t+1$, measured in terms of a somatic-tissue mass equivalent, consists of gonadic and behavioural investment and is given by the integration of the reproductive-investment rate $c w$ between ages $t$ and $t+1$ :

$$
\begin{array}{r}
\gamma_{t+1}=\int_{t}^{t+1} c w\left(t^{\prime}\right) \mathrm{d} t^{\prime}=\frac{c}{b+c}\left[w_{t}-w_{t+1}+\frac{4 a}{3(b+c)}\right] \\
\times\left(w_{t}^{3 / 4}-w_{t+1}^{3 / 4}\right)+\frac{2 a^{2}}{(b+c)^{2}}\left(w_{t}^{1 / 2}-w_{t+1}^{1 / 2}\right)+\frac{4 a^{3}}{(b+c)^{3}}\left(w_{t}^{1 / 4}-w_{t+1}^{1 / 4}\right) \\
+\frac{4 a^{4}}{(b+c)^{4}} \ln \frac{a-(b+c) w_{t}^{1 / 4}}{a-(b+c) w_{t+1}^{1 / 4}}
\end{array}
$$

The length-mass relationship applies immediately after reproduction:

$$
l_{t}=\sqrt[3]{w_{t} / k}
$$

The phenotypic mass-specific energy-acquisition rate $a$ decreases with population biomass relative to the genetically determined mass-specific energy-acquisition rate $a_{\mathrm{g}}$ because of intraspecific competition for food. For North Sea plaice, such density dependence is only important on the nursery grounds for fish smaller than $25 \mathrm{~cm}$ (Bolle et al. 2004; Rijnsdorp and Van Beek 1991); therefore, the energy acquisition of these fish depends on their total biomass $B$ : 
Table A2. Nonevolving parameters of the ecogenetic model of female North Sea plaice.

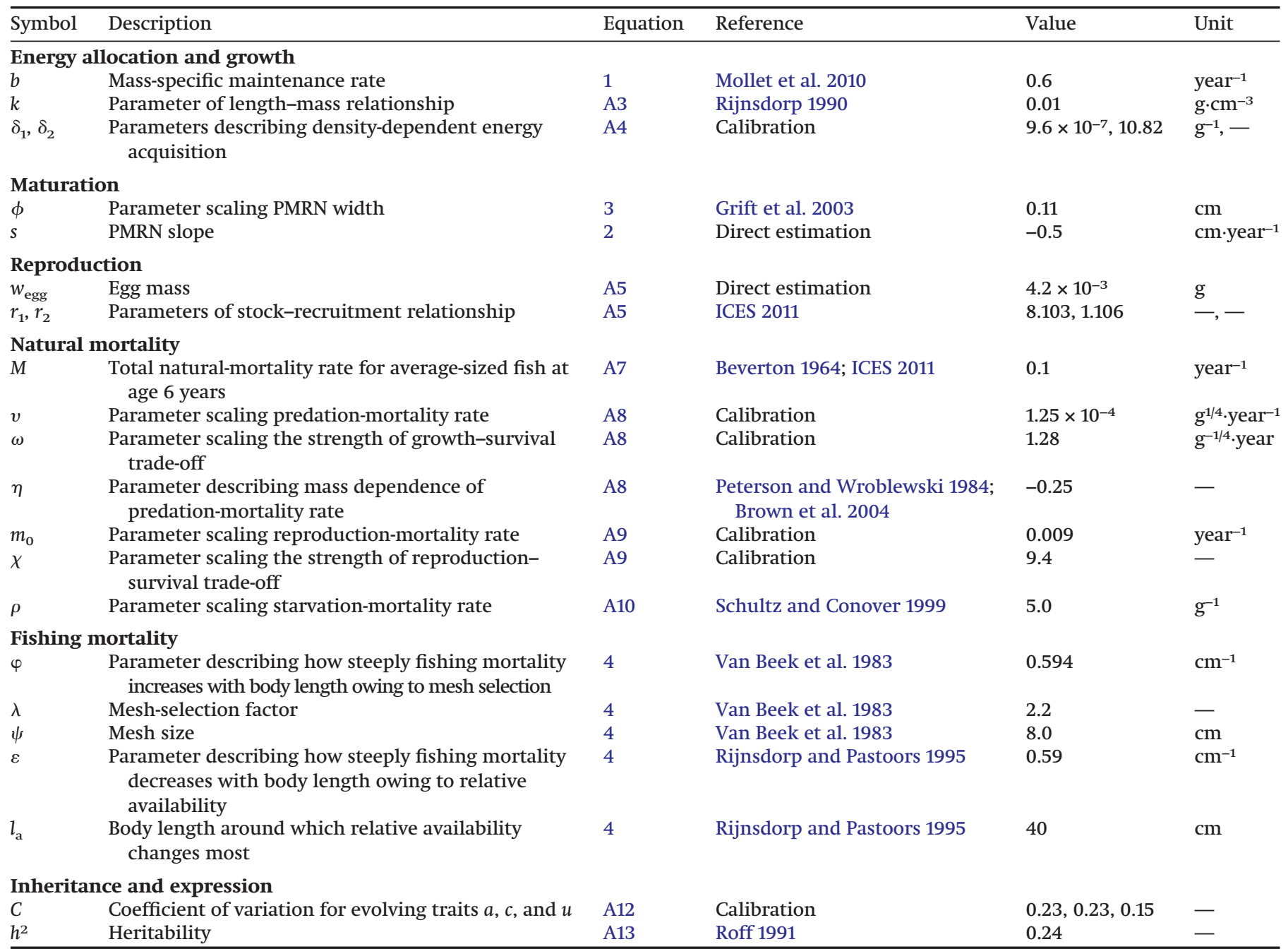

Note: As indicated under "Reference", parameter values were ( $i$ ) taken from the literature, (ii) directly estimated from empirical data on age, size, and maturity from Dutch market samples and scientific surveys, or (iii) estimated through model calibration (Mollet 2010).

$$
a=\left\{\begin{array}{cc}
a_{\mathrm{g}} /\left[1+\left(\delta_{1} B\right)^{\delta_{2}}\right] & \text { if } l \leq 25 \mathrm{~cm} \\
a_{\mathrm{g}} & \text { otherwise }
\end{array}\right.
$$

\section{Maturation}

The PMRN is determined by an intercept $u$ and a slope $s$ defining the PMRN midpoints $l_{\mathrm{p} 50}(t)$ at age $t$ according to eq. 2 . For any given age and size, the probability of maturing is given by eq. 3 .

\section{Reproduction}

The number of 1-year-old recruits is given by

$$
N_{\mathrm{r}}=\frac{r_{1}}{1+r_{2} w_{\text {egg }} / \sum_{i=1}^{n} \gamma_{i}}
$$

where $n$ is the total number of individuals, and $\gamma_{i}$ is the reproductive investment of individual $i$.

The reproductive success $\nu_{i}$ of individual $i$ is given by its individual fecundity relative to the population fecundity. Assuming a constant egg mass, fecundity is proportional to reproductive investment $\gamma$, and therefore

$$
\nu_{i}=\gamma_{i} \mid \sum_{j=1}^{n} \gamma_{j}
$$

\section{Natural mortality}

Fish are exposed to both natural and fishing mortality. The instantaneous rate $M$ of natural mortality is given by the sum of three mortality rates describing foraging mortality $m_{\mathrm{f}}$ (implying a growth-survival trade-off), reproduction mortality $m_{\mathrm{r}}$ (implying a reproduction-survival trade-off), and starvation mortality $m_{\mathrm{s}}$ (implying a maintenance-survival trade-off):

$$
M=m_{\mathrm{f}}+m_{\mathrm{r}}+m_{\mathrm{s}}
$$

Data and theory suggest that in marine systems the rate of foraging mortality due to predation scales with body size (Peterson and Wroblewski 1984; Brown et al. 2004; Savage et al. 2004). Higher mass-specific energy-acquisition rates $a_{\mathrm{g}}$ require higher foraging rates and thus higher risks of exposure to predation:

$$
m_{\mathrm{f}}=v \exp \left(\omega a_{\mathrm{g}}\right) w^{\eta}
$$

where no foraging $\left(a_{\mathrm{g}}=0\right)$ results in the baseline predationmortality rate $u w^{\eta}$.

Depletion of stored energy due to reproduction may lower survival probability (Hutchings and Myers 1994). Reproduction mor- 


\section{Pagination not final (cite DOI) / Pagination provisoire (citer le DOI)}

tality is therefore assumed to increase with the mass-specific reproductive investment $\gamma / w$ :

$$
m_{\mathrm{r}}=m_{0} \exp (\chi[\gamma / w])
$$

where no reproduction $(\gamma=0)$ results in the baseline reproductionmortality rate $m_{0}$, describing the mortality due to diseases and parasites.

If individuals do not acquire sufficient energy to cover their maintenance costs (i.e., if $a w^{3 / 4}-b w \leq 0$ ), they starve at an instantaneous mortality rate proportional to their rate of energy loss per unit of somatic mass:

$$
m_{\mathrm{s}}=\max \left(0,-\rho\left[a w^{3 / 4}-b w\right]\right)
$$

\section{Fishing mortality}

The population fishing mortality $F_{\text {pop }}$ depends on its size distribution in relation to the size-dependent exploitation pattern. We estimate $F_{\text {pop }}$ from the annual decline in the number of fish of ages 2 years and older (age 2+) between the beginnings of years $y$ and $y+1$, accounting for the proportion $p_{F, y}$ of fish that die owing to fishing mortality relative to total mortality (i.e., the sum of fishing mortality and natural mortality) during year $y$ :

$$
F_{\text {pop } y}=p_{F, y} \ln \left(N_{2+, y} / N_{3+, y+1}\right) / \text { year }
$$

To keep the population fishing mortality $F_{\mathrm{pop}, y}$ in our model equal or close to a given target mortality $F$, the maximum exploitation level $\mathrm{F}_{\max , y}$ is annually adjusted according to eq. 5.

\section{Inheritance and expression}

The genetic values of the three traits evolving in our model (mass-specific energy-acquisition rate $a$, mass-specific reproductiveinvestment rate $c$, and PMRN intercept $u$ ) are inherited from parent to offspring. Parents for each offspring are selected with a von Neumann rejection algorithm (von Neumann 1951) in proportion to the reproductive success of potential parents (eq. A6). The genetic trait values $x_{\mathrm{g}, \mathrm{o}}$ of the offspring are then sampled from a normal distribution $\mathrm{N}$ with a mean given by the mid-parental value (i.e., the average of the two parental genetic trait values $x_{\mathrm{g}, 1}$ and $x_{g, 2}$ ) and a recombination-segregation variance given by a constant coefficient of variation, $C$ :

$$
x_{\mathrm{g}, \mathrm{o}} \sim \mathrm{N}\left(\left[x_{\mathrm{g}, 1}+x_{\mathrm{g}, 2}\right] / 2,\left[C \mu_{\mathrm{g}}(x)\right]^{2}\right)
$$

where $\mu_{\mathrm{g}}(x)$ is the population's current mean genetic value of trait $x$.

These genetic trait values $x_{\mathrm{g}, \mathrm{o}}$ are translated into phenotypic trait values $x_{0}$ by sampling the latter from a normal distribution with a mean given by $x_{\mathrm{g}, \mathrm{o}}$ and an environmental variance given by a constant narrow-sense heritability $h^{2}$ (Roff 1991):

$$
x_{\mathrm{o}} \sim \mathrm{N}\left(x_{\mathrm{g}, \mathrm{o}}, \frac{1-h^{2}}{h^{2}}\left[C \mu_{\mathrm{g}}(x)\right]^{2}\right)
$$

\section{References}

Beverton, R.J.H. 1964. Differential catchability of male and female plaice in the North Sea and its effect on estimates of stock abundance. Rapp. Proc.-V. Reun. Cons. Int. Explor. Mer, 155: 103-112.

Bolle, L.J., Rijnsdorp, A.D., van Neer, W., Millner, R.S., van Leeuwen, P.I., Ervynck, A., Ayers, R., and Ongenae, E. 2004. Growth changes in plaice, cod, haddock and saithe in the North Sea: a comparison of (post-)medieval and present-day growth rates based on otolith measurements. J. Sea Res. 51(3-4): 313-328. doi:10.1016/j.seares.2004.01.001.

Brown, J.H., Gillooly, J.F., Allen, A.P., Savage, V.M., and West, G.B. 2004. Toward a metabolic theory of ecology. Ecology, 85(7): 1771-1789. doi:10.1890/03-9000.

Fonds, M., Cronie, R., Vethaak, A.D., and Van Der Puyl, P. 1992. Metabolism, food consumption and growth of plaice (Pleuronectes platessa) and flounder (Platichthys flesus) in relation to fish size and temperature. Neth. J. Sea Res. 29: 127-143. doi:10.1016/0077-7579(92)90014-6.

Grift, R.E., Rijnsdorp, A.D., Barot, S., Heino, M., and Dieckmann, U. 2003. Fisheries-induced trends in reaction norms for maturation in North Sea plaice. Mar. Ecol. Prog. Ser. 257: 247-257. doi:10.3354/meps257247.

Hutchings, J.A., and Myers, R.A. 1994. Timing of cod reproduction: interannual variability and the influence of temperature. Mar. Ecol. Prog. Ser. 108(1-2): 21-31. doi:10.3354/meps108021.

ICES. 2011. Report of the ICES Advisory Committee, 2011. ICES Advice, 2011. Books 1-11.

Mollet, F.M., Ernande, B., Brunel, T., and Rijnsdorp, A.D. 2010. Multiple growthcorrelated life history traits estimated simultaneously in individuals. Oikos, 119(1): 10-26. doi:10.1111/j.1600-0706.2009.17746.x.

Peterson, I., and Wroblewski, J.S. 1984. Mortality rate of fishes in the pelagic ecosystem. Can. J. Fish. Aquat. Sci. 41(7): 1117-1120. doi:10.1139/f84-131.

Rijnsdorp, A.D. 1990. The mechanism of energy allocation over reproduction and somatic growth in female North Sea plaice, Pleuronectes platessa L. Neth. J. Sea Res. 25: 279-290. doi:10.1016/0077-7579(90)90027-E.

Rijnsdorp, A.D., and Pastoors, M.A. 1995. Modelling the spatial dynamics and fisheries of North Sea plaice (Pleuronectes platessa L.) based on tagging data. ICES J. Mar. Sci. 52: 963-980. doi:10.1006/jmsc.1995.0092.

Rijnsdorp, A.D., and van Beek, F.A. 1991. Changes in growth of North Sea plaice (Pleuronectes platessa L.) and sole (Solea solea L.). Neth. J. Sea Res. 27: 441-457. doi:10.1016/0077-7579(91)90045-3.

Roff, D.A. 1991. The evolution of life-history variation in fishes, with particular reference to flatfishes. Neth. J. Sea Res. 27: 197-207. doi:10.1016/0077-7579 (91)90024-U.

Savage, V.M., Gillooly, J.F., Brown, J.H., West, G.B., and Charnov, E.L. 2004. Effects of body size and temperature on population growth. Am. Nat. 163(3): 429-441. doi:10.1086/381872. PMID:15026978.

Schultz, E.T., and Conover, D.O. 1999. The allometry of energy reserve depletion: test of a mechanism for size-dependent winter mortality. Oecologia, 119(4): 474-483. doi:10.1007/s004420050810.

Van Beek, F.A., Rijnsdorp, A.D., and Van Leeuwen, P.I. 1983. Results of the mesh selection experiments on sole and plaice with a commercial beam trawl vessels in the North Sea in 1981. ICES C.M. 1983/B:16.

von Neumann, J. 1951. Various techniques used in connection with random digits. Monte Carlo methods. Nat. Bur. Stand. 12: 36-38.

West, G.B., Brown, J.H., and Enquist, B.J. 1997. A general model for the origin of allometric scaling laws in biology. Science, 276(5309): 122-126. doi:10.1126/ science.276.5309.122. PMID:9082983.

West, G.B., Brown, J.H., and Enquist, B.J. 2001. A general model for ontogenetic growth. Nature, 413(6856): 628-631. doi:10.1038/35098076. PMID:11675785. 